\title{
JANELA DA ALMA: POR UMA POÉTICA DO DESFOCAMENTO'
}

\author{
Denize Correa Araujo² \\ Mas já que se há de escrever, que ao menos não \\ se esmaguem com palavras as entrelinhas. \\ $O$ melhor ainda não foi escrito. \\ $O$ melhor está nas entrelinhas. \\ Clarice Lispector
}

Quando Wim Wenders diz que poucos filmes deixam espaço para a imaginação, sem dúvida está fazendo um comentário que me parece de extrema relevância. Produzir esse espaço, para uma leitura das entrelinhas, não parece ser a tendência do momento no panorama da cinematografia universal que, como cita o cineasta alemão, nos oferece textos completos, prontos, sem preocupação quanto à existência do espectador. $\mathrm{O}$ longa Janela da Alma (João Jardim e Walter Carvalho, 2001), contudo, oferece uma alternativa sensível.

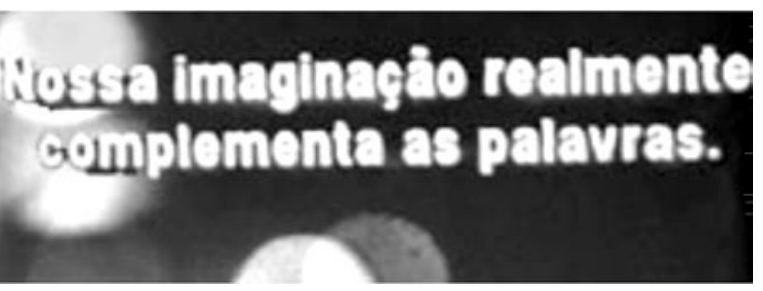

1 A inserção das imagens selecionadas para este artigo foi autorizada, em consulta por e-mail, pelo Diretor João Jardim, a quem agradeço.

2 Doutora e Coordenadora do Mestrado em Comunicação e Linguagens da Universidade Tuiuti do Paraná (UTP). [denizearaujo@hotmail.com] 
Documentário híbrido, Janela da Alma reúne entrevistas com pessoas que realmente têm outro tipo de visão, com deficiências que vão de simples miopia à cegueira total, e que oferecem depoimentos sobre o que conseguem ver e como percebem as imagens. Construído com fragmentos, o texto pode ser analisado segundo os conceitos de rizoma de Gilles Deleuze e Félix Guattari, que diferenciam a estrutura horizontal rizomática da verticalidade arbórea, pelo descentramento da primeira e lógica binária da segunda. $\mathrm{Na}$ tentativa de sintetizar e apreender os elementos mais relevantes do texto, acredito que três expressões-chave podem ser enfocadas: montagem/edição rizomática, interfaces do texto verbal e visual não padronizadas e tratamento heterogêneo do tema, três noções que levam a uma reflexão inusitada não só sobre o que vemos, mas também sobre a poética da construção do texto-desfocamento e rizoma--que esse ensaio tenta reproduzir.

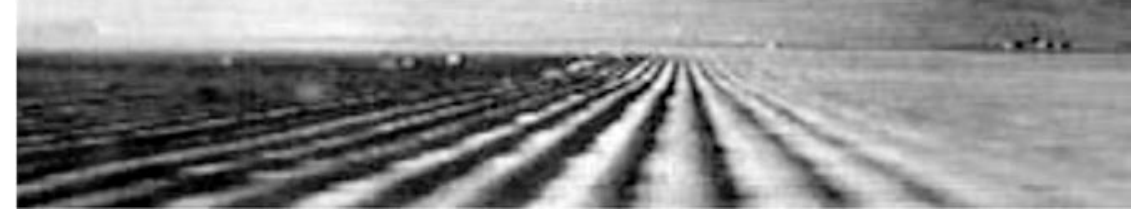

Quando perguntado sobre a razão de ter escolhido a fotografia como carreira, mesmo sendo cego, Evgen Bavcar respondeu que a imagem nem sempre está nos olhos e sim na mente (palestra no SESC-Curitiba). Feita de sombras e reflexos de luz, sua fotografia traduz as interações visão-tato e o olhar do outro.

Agnès Varda, cineasta francesa, fotografou o marido usando um suéter branco e transformou um fato trivial em uma cena atraente, capaz de fazer o espectador se concentrar mais no personagem secundário que na imagem sempre sedutora de Catherine Deneuve.

Após a cirurgia que corrigiu sua visão, Marjut Rimminen se surpreendeu com o fato de que seus amigos não perceberam o efeito da mesma, minimizando o que em sua vida inteira havia sido motivo de preocupação. 
Como esses três parágrafos anteriores, aparentemente desconectados, ou sem fio condutor, a edição de Janela da Alma parece também estar "descosturada". Esse tipo de escolha é parte do diferencial poético do filme, não só porque fala sobre o tema como porque consegue reproduzilo em sua estrutura. É como se fosse uma "poética do desfocamento", com partes de depoimentos soltos, entremeados por imagens que, como diz Wenders, oferecem ao espectador espaço para reflexão, lacunas para a imaginação. Ao contrário das costumeiras cenas de violência, miséria e marginalidade que têm povoado nossa cinematografia, Janela da Alma oferece um respiro necessário, um oásis num deserto de estereótipos, em sua grande maioria mostrados sem interrupção, como se a quantidade e a rapidez pudessem minimizar seus efeitos.

"Um rizoma não começa nem conclui, ele se encontra sempre no meio, entre as coisas, inter-ser, intermezzo.... A árvore impõe o verbo "ser", mas o rizoma tem como tecido a conjunção 'e...e...e...'. Há nesta conjunção força suficiente para sacudir e desenraizar o verbo ser" (Deleuze-Guattari, p.37).

Janela da Alma não parece ter sido editado para ter princípio, meio e fim, nem mesmo para ter links perfeitos entre uma entrevista e outra. Como citam os autores sobre a estrutura do rizoma: "qualquer ponto de um rizoma pode ser conectado a qualquer outro e deve sê-lo... diferente da árvore ou da raiz que fixam um ponto, uma ordem" (p. 15).

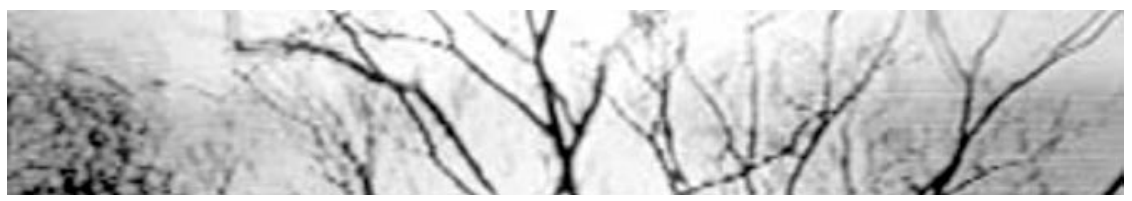

Se um rizoma é feito de linhas de segmentaridade, estratificação ou desterritorialização, também os comentários do filme seguem estratégias variadas, certas vezes conectando duas idéias, outras iniciando linhas de fuga, digressões sem volta, totalmente "desfocadas", o que fornece cada vez mais elementos para o que chamo de "poética do desfocamento", um fluir irregular, mas nem sempre, um contínuo em certos trechos, mas nem 
sempre. Focando e desfocando o tema, que por vezes versa sobre a falta de visão biológica, outras sobre uma visão cultural, de mundo, outras ainda sobre os efeitos do julgamento do outro a respeito das deficiências visuais, Janela da Alma vai conduzindo o espectador pelos seus meandros, seus atalhos, seus platôs. Parece seguir o que Wenders diz sobre colocar os óculos para poder enquadrar melhor a cena. Certas passagens do texto parecem mesmo estar mais enquadradas do que outras, mais focadas no tema; outras se desviam e tomam rumos inesperados.

Formando sinestesias visuais e auditivas, entremeando imagens de brasas ardentes e ruídos de água, desertos e luzes urbanas difusas, o filme constrói um texto visual com cenas “impressionistas", granuladas, sem explicitar detalhes, talvez seguindo o que Cildo Meireles diz, que "conhecer é destruir". Saramago comenta que se Romeu tivesse a acuidade dos olhos de um falcão talvez não teria se apaixonado por Julieta, ao ver nela todos os pequenos detalhes de sua pele, como o filme apaixonado de Agnès Varda sobre seu marido mostra. Assim, o mistério, o lugar da imaginação e a seqüência heterogênea de entrevistados constituem uma rede rizomática. Enquanto a estrutura arbórea "consiste em decalcar algo que se dá já feito, a partir de uma estrutura que sobrecodifica ou de um eixo que suporta", articulando e hierarquizando os decalques, "o mapa não reproduz um inconsciente fechado sobre si mesmo, ele o constrói....Um mapa é uma questão de performance, enquanto que o decalque remete sempre a uma presumida "competência” (Deleuze-Guattari p.21-22).

A inconsistência semântica de Janela da Alma não perturba. Ao contrário, surpreende pela variedade, pela polifonia de vozes (Bakhtin) ${ }^{3}$ nem sempre harmoniosas, pelo mosaico ímpar de citações (Kristeva) ${ }^{4}$, que assim se aceita. "Os fios de marionete, considerados como rizoma ou

3 Bakhtin usa o termo "polifonia" para textos onde os autores permitem que seus personagens se expressem em vozes distintas, individuais, únicas, independentes da voz (visão) do autor. No caso do filme em análise, considero apropriado o uso do termo, desde que essa polifonia não signifique harmonia de vozes.

4 Kristeva comenta que todos os textos contém um mosaico de citações, no sentido intertextual amplo. Nesse caso específico, estou usando a expressão no sentido restrito, do próprio filme, que propositalmente permite um mosaico de citações sobre o tema proposto. 
multiplicidade, não remetem à vontade suposta una de um artista ou de um operador...as multiplicidades se definem pelo fora: pela linha abstrata, linha de fuga ou de desterritorialização segundo a qual elas mudam de natureza ao se conectarem às outras" (Deleuze-Guattari, p.16-17).

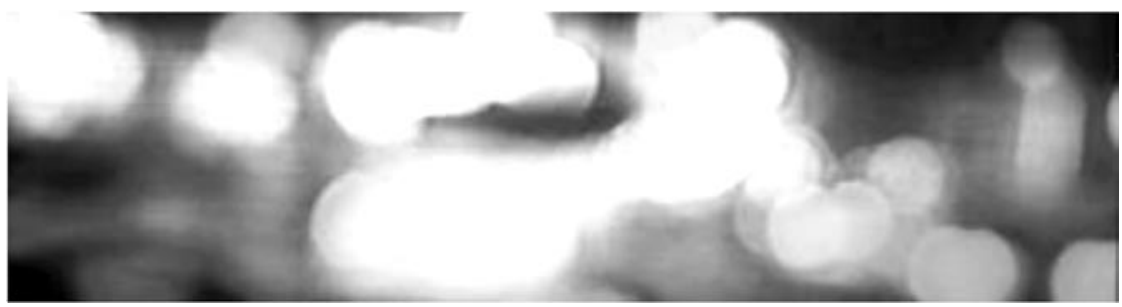

Raquel Imanishi Rodrigues, em seu artigo "Pessoal mas múltiplo”, assim define:

"O que se vê em Janela da Alma não é um conjunto equilibrado de depoimentos homogêneos, mas um composto de contribuições distintas, no qual nenhuma parte se subordina (ou reduz) às demais.... Desiguais em intensidade e poder sugestivo, os depoimentos criam um universo autônomo no qual as disfuncionalidades da deficiência visual revelam funcionalidade insuspeitada. Apontam não só modos singulares de ver e estar no mundo para os que dela padecem, mas servem para flagrar (dis)funcionalidades de ordem mais geral" (www.oficinainforma.com.br).

Há um comentário que menciona que não nos pensamos fora de foco. De fato, cartesianamente, pensamos racionalmente. Mas o onírico e o lúdico não são racionais. O rizoma como expressão do sonho e da imaginação também não o é. As imagens de entremeio, que chamo aqui de "texto visual”, são um descanso para a racionalidade e um desfocamento poético para que a mente possa sonhar, tão essenciais quanto os depoimentos do "texto verbal".

O espaço entre as tomadas é por vezes tão longo quanto as próprias entrevistas. As interfaces verbais e visuais, ou seja, a interação do texto dos 
depoimentos com as imagens nos intermezzos das mesmas nem sempre são redundantes, só certas vezes. Lucia Santaella e Winfried Nöth, em "Imagem: cognição, semiótica, mídia”, propõem a pergunta de Barthes: "será que a imagem é simplesmente uma duplicata de certas informações que um texto contém e, portanto, um fenômeno de redundância, ou será que o texto acrescenta novas informações à imagem? e citam Kalverkämper, que diferencia três casos na relação texto-imagem. O primeiro, quando a imagem só ilustra o texto, sendo redundante; o segundo, quando a imagem é mais importante que o texto e o domina. A terceira, quando a relação é de complementaridade (p. 54).

Em Janela da Alma, talvez uma quarta relação seria mais apropriada: a de descontinuidade, no sentido de relação do texto à imagem de maneira irregular, por vezes reproduzindo o que o texto diz, outra vezes desterritorializando o espectador, para mais tarde reterritorializá-lo. Essa não-continuidade rompe com o condicionamento que temos de tentar encontrar paralelismos, elementos dispostos em harmonia, imagens que se repetem em seus textos correspondentes.

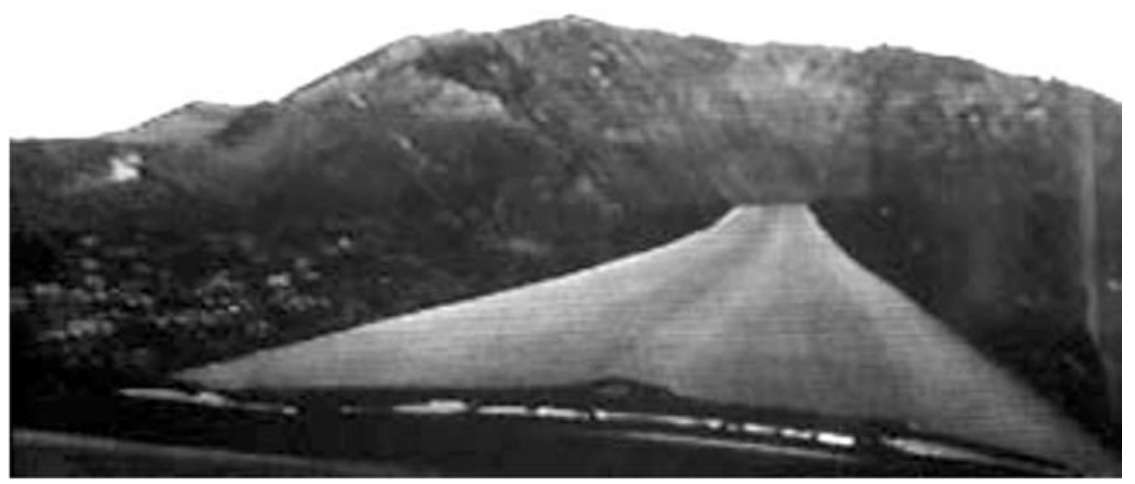

Talvez aqui seja apropriado o comentário que Deleuze faz: "o neorealismo é essa ascensão de situações puramente óticas (e sonoras, embora não houvesse som sincronizado no começo do neo-realismo), que se 
distinguem essencialmente das situações sensório-motoras da imagem-ação no antigo realismo" (p. 11). Guardadas as devidas proporções e enfocando os entremeios como "textos visuais" para a imaginação do espectador, as imagens difusas e a sonoridade produzida pelas adaptações de José Miguel Wisnik, como “opsignos" e "sonsignos"(Deleuze) ${ }^{5}$, fornecem o tempo para divagação, para assimilação e avaliação da relevância e diversidade da "visão" de cada entrevistado. O subtítulo do filme é relevante: é "um filme sobre o olhar".

O tempo de cada depoimento não parece ter sido cronometrado, nem a ordem das apresentações parece ter sido hegemônica. Assim, há ícones da literatura e do cinema ao lado de nomes não tão conhecidos, que dão seus depoimentos com a mesma relevância, favorecendo assim um dialogismo (Bakhtin) ${ }^{6}$ e uma edição rizomática (Deleuze-Guattari) ${ }^{7}$.

Barthes fala do sentido obtuso da imagem, aquele que é velado, e que, ao contrário do óbvio, nos impõe uma leitura para além do referencial, caracterizando seu processo de construção do significado ("A Câmara Clara”). Para ele, há uma diferença entre o "studium”, o óbvio, e o "punctum", o obtuso. Por "studium", Barthes entende o texto como campo do saber, por "punctum", como texto afetivo, que seduz e fascina. Enquanto o "studium" remete ao intelecto, o "punctum" remete às emoções. Embora Janela da Alma não tenha a pretensão de elaborar teses ou de exemplificar alguma, o tema e suas conotações oferecem espaço para uma leitura em ambos os sentidos. Considerando o texto verbal e o visual como complementares, há em ambos tanto apelo ao intelecto quanto ao emocional.

5 Deleuze menciona que "as situações óticas e sonoras puras podem ter dois pólos, objetivo e subjetivo, real e imaginário, físico e mental. Mas elas dão lugar a opsignos e sonsignos, que estão sempre fazendo com que os pólos se comuniquem, e num sentido ou noutro asseguram as passagens e as conversões, tendendo para um ponto de indiscernibilidade (e não de confusão)" (p. 18).

6 Para Bakhtin, o termo "dialogismo" se opõe a "monologismo", não necessariamente se referindo a "diálogo". Há monólogos dialógicos e diálogos monológicos. Aqui, estou usando "polifonia" e "dialogismo" como sinônimos, para evitar repetição.

7 Estou usando "Deleuze-Guattari” em referências ao livro "Mil Platôs" e só "Deleuze" em referências ao texto "Cinema II: a imagem-tempo", para evitar repetições desnecessárias. 


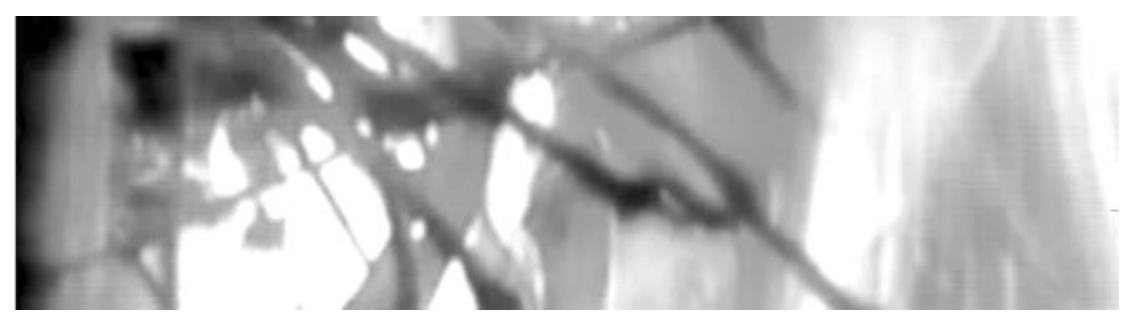

Se o que privilegia o espectador é o tempo dado à imaginação, o que singulariza o filme é a escolha do tema que, independentemente de raça ou nacionalidade, evita a já tão redundante discussão sobre problemas sociais que caracteriza a cinematografia nacional contemporânea. Reunindo quatro cineastas, dois escritores, dois poetas, duas atrizes, um músico, uma artista plástica, um professor de Literatura, um vereador, um filósofo-fotógrafo, um neurologista e duas estudantes, de várias nacionalidades, Janela da Alma transcende o regional.

[Aqui deve ser aberto um parêntesis para uma explicação necessária: não creio que o Cinema Brasileiro deva necessariamente falar sobre temas relativos à nossa sociedade, nem que não possa falar sobre eles. Minha opção seria a de ter diversos enfoques, e não só "heteronímias" (Décio Pignatari), isto é, filmes-denúncia, filmes que provocam um posicionamento político ou de gênero, fazendo com que o foco de análise nunca privilegie o estético-artístico].

A “visão imperfeita" é paradoxalmente considerada perfeita em determinadas situações, comentadas pela maioria dos entrevistados, a quem a visão interior é de maior importância.

A "poética do desfocamento" privilegia as imagens difusas, sem detalhes marcados, sem definições claras, em alusão à própria poesia, onde a subjetividade fornece subsídios para uma maior criatividade, e onde os atalhos levam a lugares inusitados.

“Às vezes é preciso restaurar as partes perdidas, encontrar tudo o que não se vê na imagem, tudo o que foi subtraído dela para torna-la “interessante”. Mas às vezes, ao contrário, é preciso fazer buracos, introduzir vazios e espaços em branco, rarefazer a imagem, suprimir dela muitas coisas que foram 
acrescentadas para nos fazer crer que víamos tudo. É preciso dividir ou esvaziar para encontrar o inteiro" (Deleuze, p. $32)$.

Se o rizoma é feito de platôs e se o platô é "uma região contínua de intensidades, vibrando sobre ela mesma, e que se desenvolve evitando toda orientação sobre um ponto culminante ou em direção a uma finalidade exterior"(Deleuze-Guattari, p.33), há platôs conectáveis em Janela da Alma: Wenders cita a imaginação, Saramago a conecta de maneira poética e transversal, mencionando "Romeu e Julieta", e Manoel de Barros a define: "o olho vê, a lembrança revê e a imaginação... a imaginação transvê , é a imaginação que transfigura o mundo”. Oliver Sacks completa: “o ato de ver, de olhar, não é só olhar lá fora. Não é só olhar para o que é visível, mas também para o invisível. De certa forma, é isso que quer dizer imaginação".

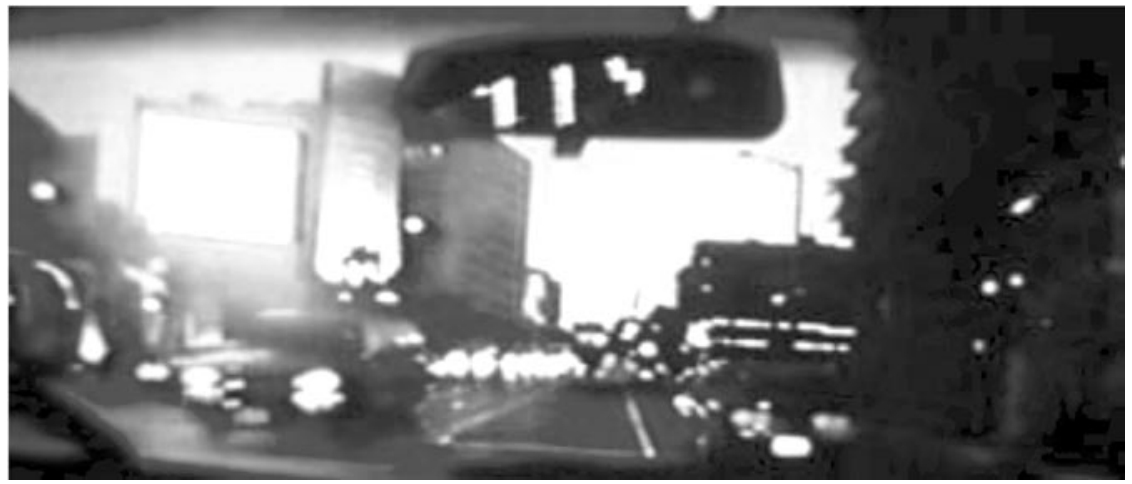

Tanto quanto os depoimentos, as imagens sugerem uma leitura "imaginada", individual e única, como os textos de literatura que são imaginados e muitas vezes decepcionantes quando mostrados na tela com a visão do diretor. Janela da Alma literalmente abre janelas ao espectador, que pode fruir do espaço e tempo a ele concedidos.

"todo rizoma compreende linhas de segmentaridade [platôs] segundo as quais ele é estratificado, territorializado, organizado, significado atribuído, etc.; mas compreende 
também linhas de desterritorialização pelas quais ele foge sem parar. Há ruptura no rizoma cada vez que linhas segmentares explodem numa linha de fuga, mas a linha de fuga faz parte do rizoma” (Deleuze-Guattari, p. 18).

Há uma linha de segmentaridade bastante longa, que termina em uma linha de fuga. Saramago e Wenders se completam ao comentar sobre a contemporaneidade, com seu excesso de imagens. Saramago acredita que estamos voltando à era da caverna de Platão, vendo sombras e crendo que são reais. Wenders argumenta que as imagens não querem "mostrar" algo e sim "vender" algo. Saramago complementa, falando sobre o excesso de jornais, o que é reiterado por Wenders, que lamenta o excesso de tudo (menos de tempo), que nos deixa sem nada. O que os aproxima ainda mais nesse platô é o tom apocalíptico e baudrillardiano empregado por ambos, que evoca o texto de Umberto Eco, "O dilúvio da informação", sobre o excesso de informação, que pode ser tão pernicioso quanto a falta dela. Saramago termina seu comentário citando Luna Park. Outro elemento de interação é a imagem, que se mescla em seus discursos, e mostra luzes de uma cidade, à noite, com palmeiras, imagem que recorre por três vezes consecutivas, como se quisesse incorporar o verbal ao visual simbioticamente.

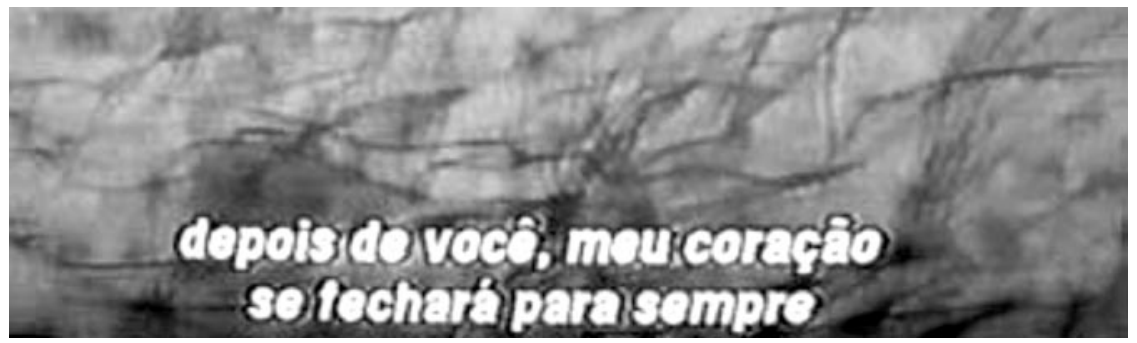

8 Eco diz que "uma boa quantidade de informação é benéfica e o excesso pode ser péssimo". Completa com um comentário de humor: "Brinco dizendo que não há diferença entre o jornal stalinista "Pravda" e o "New York Times" dominical. O primeiro não possui notícia alguma e o outro tem 600 páginas de informação. Uma semana não é suficiente para ler essas 600 páginas”. Coincidentemente, Saramago menciona 600 jornais, considerando igualmente que o excesso de informação leva ao nada. 
Esse platô é imediatamente seguido por uma linha de fuga, quando Agnès Varda inicia seu relato emocional, mudando o tom radicalmente. Recordando o marido e como ela se irritava com sua lentidão (mas no momento emocionada, talvez como no romance "Em busca de um tempo perdido" de Marcel Proust), a cineasta explica sua maneira de filmar. Seus depoimentos são uma homenagem poética a seu marido, Jacques Démy, e são permeados pelas imagens de filmes que a cineasta fez.

As imagens são variadas quanto ao tom e quanto à duração. Também não são uniformes dentro da linha narrativa, ora complementando os depoimentos de maneira não-redundante, ora mostrando exatamente o que o texto está mencionando, como quando enfoca Arnaldo Godoy e sua filhinha-bebê, logo após esse ter contado sobre o incidente na praia. Alguns depoimentos e textos visuais são em preto e branco, convidando à nostalgia, outros, misturando cores fortes, remetem ao bom humor dos entrevistados que, em sua maioria, paradoxalmente consideram a deficiência uma vantagem, como no caso de Madalena Godoy, que diz ter levado seu pai à escola diversas vezes para que os colegas vissem que ele é realmente cego. Marjut Rimminen revela, emocionada, que, determinada em vencer sua deficiência, "transformou as cinzas em jóias". Seu desejo de ser uma princesa, nas peças infantis de teatro, foi finalmente realizado com seus personagens de animação.

A atriz alemã Hanna Shygulla admira a fotografia inusitada que Bavcar fez dela, com uma coruja no ombro: "sou eu e não sou eu, Bavcar faz fotos com a mente”. Filósofo e fotógrafo, Bavcar, por sua vez, também se emociona ao contar que havia descoberto, quando jovem, que não podia ver imagens, mas podia realizá-las.

A construção deste ensaio pode ser considerada em "mise en abyme manqué”, em quatro esferas, a mais interna, que é parte do depoimento de Wim Wenders, quando este comenta sobre o tempo para a imaginação; a segunda, que é o próprio filme, que inclui esse tempo, oferecendo um texto visual tão importante quanto o verbal; a terceira, que é considerar o filme como um espaço para a imaginação, dentro da tendência oposta da cinematografia nacional; e a quarta, que é a tentativa de construir este ensaio seguindo o molde do filme. Considero um processo "manqué" por 
ser todo de maneira transversal, imperfeita, seguindo o próprio conceito da "poética do desfocamento".

\section{REFERÊNCIAS}

BAKHTIN, Mikhail. Estética da Criação Verbal. São Paulo: Martins Fontes, 1997.

BARTHES, Roland. A Câmara Clara. Rio de Janeiro: Nova Fronteira, 1984.

BAVCAR, Evgen. Os enganos do visível. NOVAES, Adauto (org.), Projeto “Muito além do espetáculo”. Palestra SESC-Curitiba, setembro 2003.

DELEUZE, Gilles. Cinema II: a imagem-tempo. SP: Brasiliense, 1990.

; GUATTARI, Félix. Mil Platôs: capitalismo e esquizofrenia. São Paulo: Ed. 34, 2000.

ECO, Umberto. “O dilúvio da informação”. Entrevista para Tânia Menai. Revista Veja, 27 dez. 2000. 
KRISTEVA, Julia. Introdução à semanálise. São Paulo: Perspectiva, 1974.

MEIRELES, Cildo. "Gramática do objeto". SÁ, Luis Felipe Sá (dir.), 15', doc.RJ, 2000.

RODRIGUES, Raquel Imanishi. "Pessoal mas múltiplo". Reportagem 35, agosto 2002 ou www.oficinainforma.com.br

SANTAELLA, Lucia; NÖTH, Winfied. Imagem, cognição, semiótica, mídia. São Paulo: Iluminuras, 1999.

Ficha Técnica do filme Janela da Alma: documentário, 73 minutos, Brasil, 2001

Direção: João Jardim e Walter Carvalho

Roteiro: João Jardim

Direção de Fotografia: Walter Carvalho

Montagem: Karen Harley e João Jardim

Distribuição: Copacabana Filmes

Entrevistados:

Agnès Varda, cineasta francesa

Antonio Cícero, poeta

Arnaldo Godoy, vereador de Belo Horizonte

Carmela Gross, artista plástica

Evgen Bavcar, filósofo e fotógrafo esloveno

Hanna Shygulla, atriz alemã

Hermeto Pascoal, músico

Jessica Silveira, menina envergonhada

João Ubaldo Ribeiro, escritor

José Saramago, Prêmio Nobel de Literatura

Madalena Godoy, filha de Arnaldo Godoy

Manoel de Barros, poeta

Marieta Severo, atriz

Marjut Rimminen, cineasta finlandesa de animação 
revista tecnologia e sociedade

Oliver Sacks, neurologista e escritor inglês

Paulo Cezar Lopes, professor de Literatura

Walter Lima Jr., cineasta

Wim Wenders, cineasta alemão. 